\title{
E्दुreatidara
}

\section{Resposta de Piaget a Vygotsky: convergências e divergências teóricas}

\section{Adrian Oscar Dongo-Montoya}

RESUMO - Resposta de Piaget a Vygotsky: convergências e divergências teóricas. Neste trabalho, ao analisar a resposta de Piaget às críticas de Vygotsky, procuramos salientar convergências e divergências teóricas básicas colocadas pelo primeiro em relação ao segundo. Para isso, num primeiro momento, analisamos os esclarecimentos de Piaget sobre a realidade do fenômeno psicológico do egocentrismo cognitivo e linguístico; num segundo momento, analisamos as relações entre as noções científicas e espontâneas na criança. Num terceiro momento, analisamos a posição diferenciada de Piaget sobre os mecanismos que explicam o desenvolvimento e progresso do conhecimento. Concluímos que, na resposta de Piaget a Vygotsky, existe clara diferenciação do seu sistema teórico.

Palavras-chave: Piaget. Vygotsky. Psicologia Genética. Desenvolvimento do Pensamento. Desenvolvimento do Conhecimento.

ABSTRACT - Piaget's Answer to Vygotsky: theoretical convergences and divergences. In analyzing Piaget's answer to Vygotsky's critics, in the present study we tried to emphasize the basic theoretical convergences and divergences appointed by the first author in relation to the second. With this in mind, as our first step, we analyzed Piaget's explanations about the reality of the psychological phenomenon of the linguistic and cognitive egocentrism; as our second step, we analyzed the relations between scientific concepts and which are spontaneously developed in the children. As our third step, we analyzed Piaget's different position about the mechanisms which explain the knowledge progress and development. We concluded that in Piaget's answer to Vygotsky there is a clear difference of his theoretical system.

Keywords: Piaget. Vygotsky. Cognitive Development. Genetic Psychology. Thought Development. 


\section{Introdução}

Estudos das obras de Piaget e Vygotsky, como os realizados por Bronkard (1985, 2000) e Melo (2008), destacam certas características da obra desses autores, notadamente a perspectiva individual atribuída ao primeiro e a perspectiva social ao segundo. Esse destaque, que se inicia com as afirmações de Vygostky $^{1}(1991)$ sobre a direção do desenvolvimento psicológico, tem-se tornado em medida comparativa e tem sido amplamente aceito no meio acadêmico e educacional. Esse parâmetro comparativo tem-se convertido, com o passar dos anos, numa ortodoxia.

Com efeito, os estudos comparativos sobre a obra desses autores permanecem ainda influenciados pelo fundo comum que se apoia nas diferenças salientadas anteriormente. Assim, na literatura existente pode-se ainda perceber o predomínio dessa solução.

Diante disso, precisamos nos perguntar se, no debate passado e atual, Piaget concordaria com essa solução amplamente divulgada e se para os estudiosos da sua obra essa solução é pertinente.

Postulamos que a resposta de Piaget (1964) às observações críticas de Vygotsky (1991) pode permitir a busca de novas soluções capazes de ultrapassar a interpretação corrente dos pensamentos de ambos e, nesse sentido, contribuir para apontar soluções ao impasse instalado quase que secularmente. Infelizmente, trabalhos nessa direção são muito escassos.

Neste trabalho, procuramos salientar as convergências e as divergências teóricas entre Piaget e Vygotsky, a partir das respostas do primeiro às observações críticas do segundo, as quais poderão orientar a nossa compreensão dos rumos seguidos por eles na constituição dos seus sistemas teóricos.

Entendemos que para o avanço do conhecimento científico, bem como para a construção da própria identidade teórica, psicológica e cultural, o que importa é determinar os processos e condições que produzem as diferenças e não as diferenças em si mesmas. Nesse sentido, concordamos plenamente com Teresa Cristina Rego (2002, p. 125-126), estudiosa da obra de Vygotsky, que defende da necessidade de examinar, com minúcia e cautela, as posições políticas, filosóficas e científicas desses dois autores, para que as complementaridades, as diferenças e até as divergências entre as teorias pudessem ser identificadas e analisadas de forma mais consequente.

É importante assinalar desde o início que as observações críticas de Vygotsky (1991) se referem às primeiras obras de Piaget, como $A$ Linguagem e o Pensamento da Criança (1999) e O Juízo e Raciocínio na Criança (1971). Nessas obras, Piaget começa a delinear alguns dos conceitos básicos da sua teoria sobre o desenvolvimento do conhecimento na criança. 
Com efeito, em resposta às observações de Vygotsky, Piaget (1964) reconhece a pertinência de algumas das críticas, sobretudo aquelas que dizem respeito à falta de precisão de alguns dos seus conceitos iniciais, mas acrescenta que precisões conceituais e maior fundamentação teórica foram feitos em trabalhos posteriores. Em tal sentido, Piaget lamenta que suas respostas à Vygotsky fossem feitas tardiamente, pois ele desconhecia os trabalhos deste importante psicólogo russo. Contudo, exprimindo um profundo respeito pelo interlocutor, se propõe responder às observações críticas, a partir de seu trabalho mais maduro e no contexto das regras do trabalho científico: reconhecimento de novos dados e realidades capazes de fundamentar novas interpretações e a reelaboração dos sistemas teóricos.

Assim, a análise da resposta de Piaget nos servirá para descobrir novas direções no que se refere às convergências e às divergências entre ambos os autores.

A nossa conjetura no desenvolvimento deste trabalho é que na resposta de Piaget existem duas orientações, a destacar: em primeiro lugar, acordo básico entre Piaget e Vygotsky sobre o papel do meio social na explicação do desenvolvimento do pensamento e da linguagem da criança, no início das suas produções teóricas. Em segundo lugar, divergência sobre o fenômeno do egocentrismo cognitivo e sobre os mecanismos de formação dos conceitos na criança. As divergências se tornaram mais claras para Piaget em função de novos dados acumulados, após longos anos de pesquisa experimental e após renovações sucessivas do seu pensamento teórico.

\section{Egocentrismo Cognitivo e Egocentrismo Linguístico}

\section{Egocentrismo Cognitivo}

Vygotsky (1991, p. 9-21) salienta que para Piaget o egocentrismo da criança é de importância fundamental na sua teoria e que a base factual é fornecida pelas pesquisas sobre o uso da linguagem pelas crianças.

Segundo Piaget, o elo de ligação de todas as características específicas da lógica das crianças é o egocentrismo do pensamento infantil. A esse traço central relaciona todos os outros que descobriu, tais como o realismo intelectual, o sincretismo e a dificuldade de compreender as relações. Ele descreve o egocentrismo como ocupando uma posição genética, estrutural e funcionalmente intermediária entre o pensamento autístico e o pensamento dirigido (Vygotsky, 1991, p. 11).

O pensamento dirigido é social, na medida em que, ao se desenvolver, vai sendo cada vez mais influenciado pelas leis da experiência e da lógica dos adultos; o pensamento autístico, ao contrário, é individualista e obedece a um conjunto de leis específicas. Entre essas duas 
formas de pensamento está o pensamento egocêntrico que participa muito mais das leis do segundo.

Assim, segundo Vygotsky (1991), a concepção do predomínio do egocentrismo da infância leva Piaget a concluir que o egocentrismo do pensamento está intimamente relacionado com a natureza psíquica da criança, que é impenetrável à experiência e às influências às quais os adultos submetem a criança.

Após reconhecer a importância do egocentrismo na teoria de Piaget, Vygotsky (1991, p. 13) questiona as suas bases de sustentação: “[...] quais fatos o levaram não apenas a aceitá-la como hipótese, mas também a depositar nela tanta confiança". Em razão disso, analisa as pesquisas realizadas por Piaget quanto ao uso da linguagem pelas crianças.

A crítica dirigida a Piaget é sobre as conclusões a que chega sobre o predomínio quantitativo do pensamento e da fala egocêntrica em relação ao pensamento e a fala socializada, bem como sobre o papel e o posterior desaparecimento desta última.

\begin{abstract}
Em sua descrição da fala egocêntrica e de seu desenvolvimento inevitável, Piaget enfatiza que ela não cumpre nenhuma função verdadeiramente útil no comportamento da criança, e que simplesmente se atrofia à medida que a criança se aproxima da idade escolar. As experiências que realizamos sugerem uma interpretação diferente. Acreditamos que a fala egocêntrica assume, desde muito cedo, um papel muito definido e importante na atividade da criança (Vygotsky, 1991, p. 14-15).
\end{abstract}

A partir de dados expostos por Piaget e daqueles que ele mesmo recolheu - notadamente sobre o coeficiente de fala egocêntrica da criança em função da variação das situações vividas pelas crianças diante de frustrações e dificuldades - Vygotsky defende que, nas situações difíceis para a criança, o coeficiente de fala egocêntrica quase se duplica em comparação com o número normal observado por Piaget. Disso deduz que a fala egocêntrica, em lugar de desaparecer, somente se oculta e se interioriza.

A hipótese de Vygotsky, bem como a sua crítica dirigida a Piaget, pode ser resumida na seguinte passagem:

Como nossas hipóteses são de âmbito limitado, acreditamos que nos ajudarão a ver, a partir de uma perspectiva nova e mais abrangente a direção geral do desenvolvimento da fala e do pensamento. Segundo Piaget, as duas funções seguem uma mesma trajetória, da fala autística à fala socializada, da fantasia subjetiva à lógica das relações. No curso dessa transformação, a influência dos adultos é deformada pelos processos psíquicos das crianças, mas acaba sendo vitoriosa. Para Piaget, o desenvolvimento do pensamento é a história da socialização gradual dos estados mentais autisticos, profundamente íntimos e 
pessoais. Até mesmo a fala social é representada como sendo subsequente, e não anterior, à fala egocêntrica (Vygotsky, 1991, p. 17).

Logo a seguir, esse autor define a sua hipótese no sentido de inverter o suposto percurso defendido por Piaget. Para isso, utiliza o desenvolvimento da linguagem.

Consideramos que o desenvolvimento total evolui da seguinte forma: a função primordial da fala, tanto nas crianças quanto nos adultos, é a comunicação, o contato social. A fala mais primitiva da criança é, portanto, essencialmente social. A princípio, é global e multifuncional; posteriormente, suas funções tornam-se diferenciadas. Numa certa idade, a fala social da criança dividi-se muito nitidamente em fala egocêntrica e fala comunicativa. (preferimos utilizar o termo comunicativo para o tipo de fala que Piaget chama de socializada, como se tivesse sido outra coisa antes de se tornar social. Do nosso ponto de vista, as duas formas, a comunicativa e a egocêntrica, são sociais, embora suas funções sejam diferentes) [...] (Vygotsky, 1991, p. 17).

Os esclarecimentos sobre as funções da fala egocêntrica podem servir para perceber possíveis encontros e desencontros entre ambos os autores.

\begin{abstract}
A fala egocêntrica emerge quando a criança transfere formas sociais e cooperativas de comportamento para a esfera das funções psíquicas interiores e pessoais. A tendência da criança a transferir para os seus processos interiores os padrões de comportamento que inicialmente eram sociais é bastante conhecida por Piaget. Em outro contexto ele descreve como as discussões entre crianças originam as primeiras manifestações da reflexão lógica. Acreditamos que algo semelhante acontece quando a criança começa a conversar consigo mesma da mesma forma que conversa com os outros. Quando as circunstâncias obrigam-na a parar e pensar, a mais provável é que ela pense em voz alta. A fala egocêntrica, dissociada da fala social geral, leva, com o tempo, à fala interior, que serve tanto ao pensamento autístico quanto ao pensamento lógico (Vygotsky, 1991, p. 17).
\end{abstract}

Observa-se nessa passagem que para os dois autores existe analogia explicativa da evolução das primeiras formas de pensamento em decorrência das ações sociais. A divergência pode-se encontrar na singularidade das explicações: para Piaget, na interiorização dos padrões sociais de discussão e para Vygotsky, na interiorização da fala egocêntrica. O encontro inicial também é reconhecido por Piaget noutro texto a ser analisado mais adiante (Piaget, 1969, p. 133).

Assim, segundo Vygotsky, a fala egocêntrica, como forma linguística, se constitui em um elo genético de extrema importância na tran- 
sição da fala oral para a fala interior, um estágio intermediário entre a diferenciação das funções da fala oral e a transformação final de uma parte da fala oral em fala interior.

\begin{abstract}
É esse papel de transição da fala egocêntrica que lhe empresta um interesse teórico tão grande. Toda a concepção do desenvolvimento da fala varia profundamente, de acordo com a interpretação que for dada ao papel da fala egocêntrica. Desse modo, o nosso esquema de desenvolvimento - primeiro fala social, depois egocêntrica, e então interior - diverge tanto do esquema behaviorista - fala oral, sussurro, fala interior - quanto da sequência de Piaget - que parte do pensamento autístico não-verbal à fala socializada e ao pensamento lógico, através do pensamento e da fala egocêntricos. Segundo a nossa concepção o verdadeiro curso do desenvolvimento do pensamento não vai do individual para o socializado, mas do social para o individual (Vygosky, 1991, p. 18).
\end{abstract}

Como se pode observar, a crítica de Vygotsky não vai dirigida ao papel do meio social na formação do pensamento lógico e comunicativo, defendida também por Piaget, mas ao papel da linguagem egocêntrica no processo de interiorização da fala, que define a direção do desenvolvimento do pensamento.

Segundo Piaget, as observações de Vygotsky ao egocentrismo cognitivo se referem ao seu significado mais comum: um individualismo que precede as relações com os outros ou hipertrofia da consciência de si. Esse significado atribuído ao egocentrismo cognitivo se deu, sobretudo, em razão de Piaget ter utilizado algumas noções psicanalíticas correntemente usadas na época da sua formulação teórica: autismo e princípio de prazer.

Em relação ao termo egocentrismo, Piaget lamenta não ter escolhido outra palavra melhor, pois isso contribuiu para que o próprio fenômeno não fosse compreendido pelos seus críticos. Em função disso, ele mesmo reconhece as observações apontadas por Vygotsky, contudo a resposta serve também como oportunidade para precisar e reafirmar a importância desse fenômeno psicológico no desenvolvimento do pensamento e do conhecimento.

Na resposta, Piaget define melhor a realidade do egocentrismo cognitivo: "Como tratei de esclarecer, o egocentrismo cognitivo se origina na falta de diferenciação entre o próprio e os outros pontos de vista possíveis, e de nenhuma forma num individualismo que precede as relações com os demais" (Piaget, 1964, p. 170, grifo nosso). Acrescenta que o egocentrismo assim definido, foi estendido, nos seus trabalhos posteriores, à análise do desenvolvimento do conhecimento no nível sensório-motor. Nesse plano de ação, mostrou que a construção de um universo objetivo e homogêneo obedece, cada vez mais, à organização das relações entre os objetos e não às atividades imediatas do sujeito, 
nem às pressões do meio. Assim, a organização da realidade exterior é consequência, simultaneamente, da superação da centração sistemática e da organização de sistemas de interpretação por parte da criança. Assim, Piaget nos estudos posteriores avança na procura das raízes do conhecimento num nível mais profundo - nos esquemas de ação - e não nas estruturas linguísticas.

Piaget salienta que não se poderia renunciar ao fenômeno do egocentrismo cognitivo, pois a sua realidade (e consequente superação progressiva) torna possível a explicação do progresso e do desenvolvimento dos conhecimentos. Para ele, o progresso do conhecimento não procede da mera adição de detalhes ou de novos níveis, como se o conhecimento mais amplo fosse somente um complemento dos anteriores mais pobres. Pelo contrário, para ele, os conhecimentos mais complexos exigem uma reformulação perpétua dos pontos de vista prévios, por meio de um processo que retrocede e avança, corrigindo continuamente tanto os erros iniciais sistemáticos como aqueles que surgem no transcorrer do caminho. Esse processo corretivo, segundo Piaget, obedece a uma lei de desenvolvimento bem definida, a lei de descentração, como ocorre com a ciência, quando ela passa da perspectiva geocêntrica para a heliocêntrica, ou como ocorre com a criança pequena, quando o conceito vovô deixa apenas de se referir à imagem de uma personagem privilegiada e passa a se referir a todas elas. É evidente que, neste segundo exemplo, a criança permanece centrada num caso particular, na medida em que não consegue colocar os indivíduos numa relação de equivalência, pois, para isso acontecer, seria preciso estabelecer relações de encaixe hierárquico do todo e da parte e renunciar à centração no caso particular.

Para Piaget, o progresso ou desenvolvimento do conhecimento se torna difícil tanto na ciência como na criança, porque o cientista e a criança precisarão vencer esses erros sistemáticos que constituem o fenômeno da centração. O desenvolvimento deixa, assim, de ser simples sucessão de fases ou níveis que se superpõem devido à ação de relações interindividuais. Ele exige, nos diversos planos, processos de superação das centrações sistemáticas e a reorganização das estruturas prévias.

Infelizmente, lamenta Piaget, o egocentrismo, como fenômeno psicológico de centração, não foi percebido por Vygotsky; do contrário, possivelmente isso tivesse contribuído para uma aproximação teórica mais substancial entre os dois autores.

\section{Egocentrismo Linguístico}

É possível estender o fato do egocentrismo cognitivo, como fenômeno de centração, para a análise das trocas linguísticas?

Para Vygotsky essa possibilidade não seria possível, visto que este autor mostrou, como diz o próprio Piaget, desinteresse em conhecer 
a própria realidade do egocentrismo cognitivo. Desse modo, segundo Piaget (1964), as críticas dirigidas às suas pesquisas sobre a linguagem infantil se dirigiram a questões estatísticas antes que à realidade do egocentrismo linguístico. Assim, declara que muitos dos críticos se dedicaram a considerar o número de orações nas quais a criança fala de si mesma como medida de linguagem egocêntrica, como se não se pudesse falar de nós mesmos de um modo que não fosse egocêntrica.

A seguir, Piaget afirma que seus críticos se detiveram na observação do primeiro capítulo da sua obra $A$ Linguagem e o Pensamento da Criança (1999). Nesse capítulo, Piaget coloca como manifesto um inventário da fala espontânea da criança, tratando de distinguir os monólogos individuais e os monólogos coletivos das comunicações adaptativas (cooperativas). No segundo e no terceiro capítulo, estuda as conversações e os argumentos das crianças, os quais visam superar os seus próprios pontos de vista. No entanto, esses estudos não foram levados em consideração pela crítica.

Quanto a essa forma de tratamento dos dados acumulados por ele mesmo, Piaget lamenta:

O fenômeno mesmo, cuja frequência relativa nos diferentes níveis de desenvolvimento tratamos de provar, assim como seu declínio com a idade, não foram jamais discutidos, visto que foram pouco entendidos. Quando foi considerado em termos de centração distorcida da própria ação e da sua descentração posterior, este fenômeno resultou ser muito mais significativo no estudo das ações mesmas e da sua interiorização na forma de operações mentais que no campo da linguagem. No entanto, ainda pode ser possível um estudo mais sistemático das discussões das crianças, e especialmente da conduta dirigida (em companhia da fala), para outorgar índices válidos de medida para sua verificação e prova (Piaget, 1964, p. 173, grifo nosso).

Salientamos dois comentários de Piaget sobre as críticas de Vygotsky ao egocentrismo linguístico.

Por uma parte, diz Piaget (1964, p. 173), Vygotsky não se dá conta de que o fenômeno do egocentrismo envolve um problema real e não simplesmente uma questão de estatística. Vygotsky verifica os fatos da linguagem egocêntrica através de "artifícios de medição" e observações sobre a sua frequência e a sua diminuição quando começa a formar-se a fala interiorizada. Sobre a hipótese de Vygotsky, a fala egocêntrica como ponto de partida para o desenvolvimento da linguagem interiorizada, Piaget concorda, apesar do fenômeno da centração não ter importância na teoria de Vygotsky.

Por outra parte, o que acredito que ele deixou de considerar é o egocentrismo mesmo como obstáculo principal para a coordenação e cooperação de distintos pontos de vista. Vygotsky me reprova não ter enfatizado suficiente- 
mente, desde o começo, o aspecto funcional destes problemas. Concedido! Mas devo manifestar que fiz mais adiante. No Ojuízo moral na criança estudei jogos grupais (das bolinhas, etc.) e constatei que antes dos sete anos de idade não sabem como coordenar as regras durante o jogo, de modo que cada um joga para si mesmo, e todos ganham sem entender que o importante é a competição. R.F. Nielsen ${ }^{1}$ que estudou as atividades de cooperação (como construção, etc.) descobriu no campo da ação mesma todas as características que eu enfatizei a respeito da linguagem. Portanto, existe um fenômeno geral que Vygotsky tem descuidado (Piaget, 1964, p. 174).

Por outra parte, para Piaget o conceito de socialização de Vygotsky é muito amplo e indiferenciado. Com efeito, quando Vygotsky defende que a primeira função da linguagem deve ser a comunicação global, e que a fala posterior se diferencia em egocêntrica e comunicativa propriamente dita, Piaget se mostra de acordo; mas, quando Vygotsky defende que essas duas formas linguísticas são igualmente socializadas, e que somente diferem na sua função, Piaget se mostra radicalmente em desacordo, pois o termo socialização é amplo demais.

Segundo Piaget, se um indivíduo A crê equivocadamente que outro indivíduo $\mathrm{B}$ pensa igual a $\mathrm{A}$, e se não trata de entender a diferença entre os dois pontos de vista, isso é, sem dúvida alguma, um comportamento social, no sentido em que existe um contato social entre os dois, porém tal conduta não é adaptada do ponto de vista da cooperação intelectual. Assim, para Piaget a própria socialização decorre do fato da superação do egocentrismo, como centração no próprio ponto de vista, e lamenta que Vygotsky não o tenha percebido: "Esse ponto de vista é o único aspecto do problema que me tem preocupado, mas que parece não ter interessado a Vygotsky" (Piaget, 1964, p. 174). seria este:

Para Piaget (1964, p. 175), o significado válido de egocentrismo

\begin{abstract}
A falta de descentração da atitude para mudar de perspectiva mental, nas relações sociais, assim como com as coisas. Mais ainda, acredito que é precisamente a cooperação com os outros (no plano cognitivo) o que nos ensina a falar de 'acordo' aos demais e não simplesmente desde nosso ponto de vista.
\end{abstract}

Mas, como se explica o fenômeno da centração na teoria de desenvolvimento de Piaget?

A centração inicial e sistemática deriva do fato de a criança estabelecer uma relação de simples continuidade entre suas ações e os objetos do mundo exterior: o mundo para a criança é uma extensão dos seus esquemas iniciais de ação e que a dualidade entre o eu e o mundo somente será conquistada após um longo processo construtivo de sistemas de interpretação e de renúncia à centração. Esse fato se verifica 
também no plano da representação, quando da necessidade de conquista dos objetos distantes no tempo e no espaço.

Podemos concluir, portanto, que as divergências entre os dois autores, colocadas por Piaget, relativas ao egocentrismo e à socialização, parecem levar a configurar, na realidade, duas concepções diferentes de desenvolvimento: por um lado, a concepção proposta por Vygotsky, para quem direção do desenvolvimento iria do social ao individual, em contraposição à direção oposta, atribuída a Piaget; por outra, a de Piaget, que insistindo no reconhecimento de processos de reorganizações e superações de erros sistemáticos (centrações) questiona as noções de desenvolvimento linear: do individual para o social ou do individual para o social.

Essa diferença se mostrará mais evidente em relação aos mecanismos psicológicos responsáveis pelo desenvolvimento: generalização perceptiva versus generalização operatória, os quais serão tratados na parte final deste trabalho.

\title{
Noção de Adaptação
}

Segundo Vygotsky, a teoria de Piaget, apesar de pretender se afastar das teses dicotômicas, separa ainda a necessidade e o prazer da adaptação à realidade; portanto apresenta ainda impasse teórico fundamental na psicologia.

\begin{abstract}
A estrutura básica da teoria de Piaget apoia-se no pressuposto de uma sequência genética de duas formas opostas de intelecção, as quais, segundo a teoria psicanalítica, servem ao princípio do prazer e ao princípio de realidade. Do nosso ponto de vista, o impulso para a satisfação das necessidades e o impulso para a adaptação à realidade não podem ser considerados como coisas separadas entre si e mutuamente opostas. Uma necessidade só pode ser verdadeiramente satisfeita mediante uma certa adaptação à realidade (Vygotsky, 1991, p. 19) .
\end{abstract}

Para Vygotsky, portanto, o pensamento autístico resulta de um desenvolvimento tardio, consequência da diferenciação do pensamento realista e conceitual. O autismo é um dos efeitos da polarização e diferenciação das diversas funções do pensamento. Além disso, a fala egocêntrica não paira no vazio, mas tem uma relação direta com o modo como a criança lida com o mundo real.

Assim, para esse autor, a natureza do pensamento egocêntrico postulado por Piaget - com a sua característica de sincretismo - não tem uma base científica segura nem uma aplicação para todas as sociedades (universalidade).

Diante das críticas colocadas por Vygotsky em relação à questão da adaptação, Piaget concorda, mas esclarece que nas suas obras se- 
guintes esse conceito foi reformulado completamente. Principalmente em seus trabalhos da década de 30, notadamente em O Nascimento da Inteligência na Criança (1987), no qual procura mostrar a gênese do pensamento no contexto da adaptação, que integra questões de necessidade e adaptação à realidade como elementos indissociáveis. A adaptação, nesse novo contexto, está ligada à ação e é entendida como equilíbrio (estável ou instável) ou processo de equilibração entre as atividades de assimilação e de acomodação dos esquemas de ação (sensório-motores ou conceituais). É justamente nesse processo adaptativo que o fenômeno do egocentrismo se torna importante.

Quanto à questão da universalidade das hipóteses de Piaget sobre o egocentrismo cognitivo e linguístico, Vygotsky (1991, p. 21) afirma que: "As uniformidades de desenvolvimento estabelecidas por Piaget aplicam-se ao meio dado, nas condições em que Piaget realizou seu estudo. Não são leis da natureza, mas sim leis históricas e socialmente determinadas".

Logo a seguir reafirma:

De nossa parte estamos convencidos de que o estudo do desenvolvimento do pensamento em um meio social diferente, em especial de crianças que, ao contrário das estudadas por Piaget, trabalham, levará com certeza a resultados que nos permitirão formular leis com uma esfera de aplicação muito mais ampla (Vygotsky, 1991, p. 21).

Sobre essas críticas, Piaget prefere não responder, pois, como se sabe, nas décadas que se seguiram, foram realizadas, nas mais variadas latitudes, pesquisas comparativas que mostraram a importância explicativa da noção de egocentrismo.

\section{Aprendizagem Escolar, Conceitos Espontâneos e Científicos}

No capítulo sexto do livro Pensamento e Linguagem, Vygotsky (1991) analisa algumas teorias sobre a relação entre conceitos espontâneos e não espontâneos, em particular os conceitos científicos, e sobre essa base formula a sua própria concepção teórica.

Declara que ao se estudar a formação de conceitos na infância, a maioria dos pesquisadores usam os conceitos cotidianos formados pela criança sem a ajuda do aprendizado sistemático, pois supõem que as leis baseadas nesses dados se apliquem também aos conceitos científicos da criança. Entretanto, segundo ele, somente alguns dos mais perspicazes estudiosos modernos do pensamento infantil, como Piaget, questionam a validade dessa extensão.

Piaget estabelece uma nítida fronteira entre as ideias da criança acerca da realidade, desenvolvidas principalmen-

Educação \& Realidade, Porto Alegre, v. 38, n. 1, p. 271-292, jan./mar. 2013

Disponível em: <http://www.ufrgs.br/edu_realidade> 
te mediante seus próprios esforços mentais, e aquelas que foram decididamente influenciadas pelos adultos; ele denomina o primeiro grupo de espontâneas e o segundo de não espontâneas, e admite que o último grupo pode merecer uma investigação independente. A esse respeito, vai além e mais fundo do que qualquer outro estudioso dos conceitos infantis [...] (Vygotsky, 1991, p. 73).

Em seguida, acrescenta a existência de erros no raciocínio de Piaget que depreciam o valor das ideias das crianças.

\begin{abstract}
Embora defenda que, ao formar um conceito, a criança o marca com as características da sua própria mentalidade, Piaget tende a aplicar essa tese apenas aos conceitos espontâneos, e presume que somente estes podem nos elucidar as qualidades especiais do pensamento infantil: ele não consegue ver a interação entre os dois tipos de conceitos e os elos que os unem num sistema total de conceitos, durante o desenvolvimento intelectual da criança. Esses erros conduzem-no a outro [...] (Vygotsky, 1991, p. 73).
\end{abstract}

O outro erro de Piaget seria a incoerência teórica entre o seu postulado da socialização progressiva, determinante na evolução do pensamento, e a pouca importância atribuída à aprendizagem escolar. Vygotsky afirma "Essa incoerência é o ponto fraco da teoria de Piaget, tanto em termos teóricos quanto práticos” (Vygotsky, 1991, p. 73).

Esse suposto erro é salientado pelo conceito de socialização formulado por Piaget e interpretado por Vygotsky como abolição mecânica das características do próprio pensamento da criança. Vejamos:

Teoricamente, a socialização do pensamento é vista por Piaget como uma abolição mecânica das características do próprio pensamento da criança, seu enfraquecimento gradual. Tudo o que é novo no desenvolvimento vem do exterior, substituindo os próprios modos de pensamento da criança. Durante toda a infância há um conflito incessante entre as duas formas de pensamento mutuamente antagônicas, com uma série de acomodações em cada nível de desenvolvimento sucessivo, até que o pensamento adulto acabe por predominar. A própria natureza da criança não desempenha nenhum papel construtivo em seu progresso intelectual. Quando Piaget diz que nada é mais importante para o aprendizado eficaz do que um conhecimento completo do pensamento espontâneo da criança [33], ele está aparentemente sendo induzido pela idéia de que é preciso conhecer o pensamento infantil tanto quanto se deve conhecer um inimigo, a fim de se combatê-lo com êxito (Vygotsky, 1991, p. 74, grifo nosso).

Diante dessa afirmação, Piaget se pronuncia de maneira veemente pelo desconhecimento do seu trabalho. Para ele, esse erro é grave, pois justamente a sua teoria é julgada como a concepção contrária: "Na 
realidade, ainda hoje me atribuem a interpretação do desenvolvimento espontâneo como tendendo por si mesmo para as estruturas lógicomatemáticas do adulto; como um ideal predeterminado!” (Piaget, 1964, p. 177).

Para Piaget, existiriam na realidade outras questões mais profundas que poderiam marcar coincidências e fronteiras entre ambos os autores, referidas à interpretação dos conceitos espontâneos e não espontâneos e à interpretação da relação entre os conceitos espontâneos e científicos.

\title{
Relação entre Conceitos Espontâneos e Não Espontâneos (Escolares)
}

Do nosso ponto de vista, existe convergência entre os autores estudados sobre a inter-relação entre os conceitos científicos e espontâneos, sobre a relação entre o aprendizado escolar e o desenvolvimento mental da criança, apesar de Vygotsky interpretar a concepção de Piaget, sobre esse tema, como velha e tradicional.

\begin{abstract}
Essa concepção, característica da velha teoria educacional, também impregna os escritos de Piaget, que acredita que o pensamento da criança passa por certas fases e estágios, independentemente de qualquer instrução que ela possa receber; a instrução permanece um fator externo. $\mathrm{O}$ nível do desenvolvimento da criança não deve ser avaliado por aquilo que ela aprendeu através da instrução, mas sim pelo modo como ela pensa sobre assuntos a respeito dos quais nada lhe foi ensinado. Aqui, a separação - na verdade, a oposição - entre aprendizado e desenvolvimento é levada ao seu extremo [...] (Vygotsky, 1991, p. 82).
\end{abstract}

Piaget questiona essa forma de caracterizar a sua concepção que reproduz a crítica do senso comum às suas pesquisas psicológicas. $\mathrm{Na}$ medida em que sempre se preocupou em superar teorias educacionais que postulam relações unilaterais e dicotômicas, questiona a excessiva confiança depositada na instrução do adulto. Assim, segundo ele (1964), o que se transmite através da instrução, em alguns casos pode ser bem assimilado pela criança, desde que, de fato, seja uma extensão de algumas das suas construções espontâneas. Em tais casos, seu desenvolvimento se acelera. Em outros casos, quando os conteúdos que se atribuem à instrução se apresentam demasiado cedo ou demasiado tarde, ou de um modo que impedem a assimilação porque não estão de acordo com as suas construções espontâneas, então impede o desenvolvimento da criança ou se desvia de modo estéril, como acontece frequentemente com o ensino das ciências exatas.

Portanto - diz Piaget - eu não acredito, como parece ocorrer com Vygotsky, que os novos conceitos, sobretudo no 
nível escolar, se adquiram sempre através da intervenção didática do adulto. Isso pode ocorrer, mas existe uma forma de instrução muito mais produtiva, a chamada "escola ativa" que procura criar situações, que, embora não sejam "espontâneas" em si mesmas, incitam a uma elaboração espontânea por parte da criança, se conduz de forma a despertar seu interesse e apresente o problema de um modo tal que corresponda às suas estruturas formadas por ele mesmo (Piaget, 1964, p. 178).

O que Piaget estaria defendendo é que a elaboração e recriação dos conceitos científicos por parte da criança sejam garantidas pelo engajamento delas em atividades de pesquisa, de produção intelectual e diálogo e não simplesmente pela atividade instrutiva do professor.

\title{
Relação entre os Conceitos Espontâneos e Científicos
}

Para Vygotsky (1991), o ponto chave desta questão é que os conceitos científicos e espontâneos começam em pontos diferentes, contudo se encontram eventualmente. Para Piaget, sobre isso haveria completo acordo, se o encontro garantisse a contribuição solidária e irredutível entre a psicogênese e sociogênese e não a simples determinação da psicogênese pelo ambiente histórico-cultural.

\begin{abstract}
Sobre isto estamos completamente de acordo, se significa que se produz um encontro real entre a sociogênese das noções científicas (na história da ciência e na transmissão de um conhecimento de uma geração à seguinte) e a psicogênese das estruturas espontâneas (incluídas, com certeza, pela interação com o meio social, familiar, escolar, etc.) e não simplesmente que a psicogênese seja integralmente determinada pelo meio ambiente histórico e cultural [...] (Piaget, 1964, p. 178, grifo nosso).
\end{abstract}

Piaget esclarece que ele não diz nada além do expresso pelo próprio Vygotsky, já que ele admite, de bom grado, a espontaneidade no desenvolvimento. Por isso, é preciso determinar o significado de espontaneidade da criança e do sujeito do conhecimento, em função da análise dos mecanismos que possibilitam a construção do pensamento e do conhecimento da criança.

Por outro lado, segundo Piaget, existiria coincidência entre os dois autores sobre interesse pelo estudo dos conceitos científicos. Piaget sublinha a existência de coincidências no que diz respeito aos projetos iniciais. Se para Vygotsky a tarefa fundamental da psicologia infantil é estudar os conceitos científicos, seguindo passo a passo o processo que se desenvolve na criança, para Piaget essa tarefa foi também objetivo fundamental na sua carreira como pesquisador; para este, seus primeiros livros apenas constituíam uma introdução. Em razão disso, para este autor, os trabalhos, como A Gênese do Número na Criança (1981), O 
Desenvolvimento das Quantidades Físicas na Criança (1983), A Formação da Noção de Força (1973a), A Transmissão dos Movimentos (1972a), As Noções de Movimento e de Velocidade na Criança (1972b), A Geometria Espontânea na Criança (1948), As Explicações Causais (1971a), Gênese das Estruturas Lógicas Elementares (1971b), O Desenvolvimento da Noção de Tempo na Criança (1946), A Composição das Forças e o Problema dos Vetores (1973b), A Direção dos Móbiles (1972c), A Representação do Espaço na Criança (1993d), A Gênese da Ideia de Azar na Criança (1951), constituem pesquisas sobre o desenvolvimento dos conceitos científicos básicos na criança.

\section{A Questão do Motor do Desenvolvimento e os Mecanismos Construtivos}

É na determinação dos mecanismos explicativos da formação dos conhecimentos espontâneos e não espontâneos que se pode perceber a existência das divergências fundamentais entre a teoria de Vygotsky e a de Piaget. Segundo Piaget (1964, p.179), essas divergências constituem a extensão do problema apontado nos itens anteriores, sobretudo da questão do egocentrismo.

\section{A Explicação do Atraso do Conhecimento Consciente}

Para Piaget (1964, p. 179), quando Vygotsky quer explicar a manifestação tardia da consciência e do conhecimento, Vygotsky se restringe a expor os fatos e não a penetrar nas causas do fenômeno. Desse modo, embora Vygotsky estivesse certo ao analisar o desenvolvimento tardio do conhecimento como resultado da conhecida lei do "acordo", segundo a qual a consciência e o controle aparecem somente numa etapa final do desenvolvimento de uma função, e da lei de "tomada de consciência”, segundo a qual o conhecimento está limitado inicialmente aos resultados de ações e somente mais tarde se estende ao "como", ele somente expõe os fatos e não a explicação. A explicação começaria, segundo Piaget, quando da descrição se passa ao modo de produção dos fenômenos, para o qual os processos de centração e descentração seriam absoltamente necessários.

Para Piaget, então, deixar de lado os processos de centração e descentração na explicação do desenvolvimento tardio da consciência reduz a interpretação do desenvolvimento psicológico a uma forma simples e linear. Em função disso, Piaget declara: "Essa diferença em perspectiva entre um simples esquema linear como o de Vygotsky e outro de um esquema de descentração se faz mais evidente na questão do motor principal do desenvolvimento intelectual” (Piaget, 1964, p. 179).

Educação \& Realidade, Porto Alegre, v. 38, n. 1, p. 271-292, jan./mar. 2013.

Disponível em: <http://www.ufrgs.br/edu_realidade> 


\section{A Generalização Perceptiva e Generalização Operatória como Motores Principais do Desenvolvimento Intelectual}

Segundo Piaget (1964), Vygotsky (1991, p. 71-101) defende que o fator principal do desenvolvimento intelectual é a "generalização das percepções”, e que este mecanismo seria suficiente em si mesmo para introduzir as operações mentais na consciência.

Contrariamente a essa posição, para Piaget, que explorou e iniciou a pesquisa do desenvolvimento espontâneo das noções científicas (espaço, tempo, causalidade, objeto, substância, força, número, classes, séries, etc.), o fator central do desenvolvimento não é a generalização perceptiva, mas sim a construção de operações, que consiste em sistemas de ações interiorizadas que se coordenam entre si sobre formas reversíveis, sujeitas a leis de composição bem definidas (grupamentos e grupos). Assim, para Piaget, o progresso da "generalização das percepções" seria somente o resultado da elaboração das estruturas operatórias, e estas não derivam da percepção, mas sim da ação total. Em diferentes obras que se seguiram após a década de 1940, Piaget (1974a, 1974b, 1974c, 1995, 1978) desenvolve o conceito de generalização construtiva ou generalização operatória como um dos mecanismos centrais do progresso e do desenvolvimento do conhecimento na criança e na própria ciência.

Segundo Piaget (1964), Vygotsky esteve próximo dessa solução, quando defendia que o sincretismo, a justaposição, a insensibilidade à contradição e outras características do nível pré-operatório da criança, se devem à falta de sistema. Entretanto, esses sistemas não são simplesmente, como afirma Vygotsky, o produto da generalização perceptiva. Pelo contrario, na teoria de Piaget, esses sistemas são estruturas operatórias múltiplas e diferenciadas, cuja elaboração gradual por parte da criança se realiza, progressivamente, através de "abstrações reflexionantes” e a partir da coordenação dos esquemas de ações (sistemas de ação que obedecem a leis de totalidade).

Quando Vygotsky comenta sobre a inclusão de classes, diz Piaget (1964), tem-se a impressão de que a criança descobre a inclusão por uma generalização e aprendizagem empírica. Para Piaget, que foi pioneiro no estudo dessas questões, esse processo é muito mais profundo e complexo. Para lograr a inclusão, a criança deve organizar um sistema operatório tal que A (rosas) + A' (outras flores que não são rosas) = B (flores), e que se $\mathrm{A}=\mathrm{B}-\mathrm{A}^{\prime}$, consequentemente $\mathrm{A}<\mathrm{B}$. Assim, a reversibilidade desse sistema é um pré-requisito para a inclusão.

Desse modo, quando Piaget reflete em pensamento espontâneo não está se referindo à insensibilidade do sujeito à ação escolar, mas sim à necessidade de considerar a atividade construtiva do sujeito, isto é, à atividade operatória na composição e significação dos dados exteriores. Essa atividade não se efetua isoladamente nem unilateralmente por 
parte do indivíduo, mas sim no seio de trocas interindividuais, como teremos oportunidade de evidenciar no próximo item.

\section{Conceito de Socialização}

Como foi observado num item anterior, para Vygotsky (1991) o conceito de socialização de Piaget significa uma abolição mecânica das características do próprio pensamento da criança e que tudo o que é novo no desenvolvimento vem do exterior, substituindo os próprios modos de pensamento da criança.

Essa afirmação teria sentido se considerarmos as primeiras hipóteses explicativas do desenvolvimento do pensamento infantil, feitas por Piaget. Nossos estudos da obra dele mostram que este autor, no período inicial de elaboração da sua teoria, explica a evolução do pensamento da criança em função da ação do meio social e cultural, particularmente da interação social. No entanto, ele mesmo faz a autocrítica de que, nessa época, lhe escapava a explicação psicologia endógena, ou seja, os mecanismos internos de formação. Noutras palavras, a interiorização da língua e a interação social - troca e cooperação entre indivíduos - estariam explicando, nesse período, a evolução do pensamento e da linguagem. Nesse sentido, pode-se dizer que a tese de Piaget, nesse período, representa uma forma de reducionismo social.

Essa conjetura encontra-se confirmada numa passagem do artigo redigido em 1969, pelo próprio Piaget, a propósito do reducionismo social.

Tal modo de explicação se encontra atualmente em todos os campos da afetividade elementar (Psicanálise chamada culturalista: E. Fromm, etc.) e das condutas em geral (R Benedict; M. Mead, etc.) até as reações cognitivas (desde M. Baldwin e P. Janet, até os trabalhos de Vygotsky e Luria sobre o papel da linguagem, passando por nossas próprias obras iniciais) e as condutas propriamente sociais (sociometria, etc.) [...] (Piaget 1969, p. 133).

O princípio utilizado pelas concepções reducionistas segundo Piaget é o mesmo: quando um comportamento novo vem enriquecer os precedentes, no decurso do desenvolvimento, seria devido menos a uma construção interna (fator endógeno) do que a um resultado das próprias interações da vida social (fator exógeno).

Como se pode observar, nesse período inicial encontramos maior aproximação entre Piaget e Vygotsky, no que se refere à questão da ação do meio social.

Contudo, apesar dessa aproximação, ainda nesse período, o conceito de socialização para Piaget já é restrito e não se identifica com o termo "vida social" no seu significado genérico. Portanto, desenvolvimento do pensamento não poderia significar passagem da vida individual para a vida social, mas sim passagem de uma forma de vida social,

Educação \& Realidade, Porto Alegre, v. 38, n. 1, p. 271-292, jan./mar. 2013.287

Disponível em: <http://www.ufrgs.br/edu_realidade> 
centrada no próprio ponto de vista, para outra, descentrada e capaz de verdadeira cooperação (socializada).

Com efeito, na resposta, Piaget (1964) frisa que, se desde o começo a criança manifesta vida social no seu contato e na sua comunicação com os outros, ela não consegue, nessas relações, levar em conta a perspectiva dos outros. Daí, o conceito de socialização ser restrito e se referir à condição de estabelecer interação e troca levando em conta as perspectivas alheias, o que inaugura a verdadeira cooperação e acordo mútuo.

O estudo das operações, como processos endógenos do sujeito, conduz Piaget a evidenciar a questão da socialização e do egocentrismo (centração - descentração) numa nova luz, muito mais precisa e elaborada que nas suas primeiras obras.

Assim, para Piaget, o pensamento lógico (operatório) é socializado na medida em que implica a possibilidade de comunicação entre os indivíduos capazes de diferenciação dos seus pontos de vista; reciprocamente, a socialização exige um pensamento lógico na medida em que requer a participação de sujeitos que organizam seus conceitos em sistemas de composição (grupos e agrupamentos).

\begin{abstract}
Mas, tal troca interpessoal se efetua através de correspondências, reuniões, intersessões e reciprocidade, isto é, através de operações. Desse modo, existe identidade entre as operações intrapessoais e as interpessoais que constituem a co-operação no exato e quase etimológico sentido da palavra. As ações, já sejam individuais ou interpessoais, estão em essência coordenadas e organizadas por estruturas operatórias construídas espontaneamente no curso do desenvolvimento intelectual (Piaget, 1964, p. 180181, grifo nosso).
\end{abstract}

Nesse sentido, a teoria de Piaget apresenta a necessidade de colocar a importância da sociedade e da cultura no desenvolvimento individual em novas bases, pois a questão fundamental é estabelecer - ou restabelecer - a verdadeira relação entre o desenvolvimento do indivíduo e da sociedade.

Após os primeiros trabalhos sobre a socialização, Piaget formula, com maior precisão, a solidariedade e a irredutibilidade entre as trocas ou coordenações intraindividuais (processos endógenos, como a generalização operatória, etc.) e as trocas e coordenações interindividuais (processos exógenos, como as interações coletivas). Trabalhos iniciais, como A Representação do Mundo na Criança (1947) e O Juízo Moral na Criança (1994), já formulam essa indissociabilidade. A obra Études Sociologiques (1977) mostra um conjunto de estudos realizados por esse autor sobre os progressos correlativos entre indivíduo e sociedade na psicogênese e na história das sociedades. Num desses estudos, a questão principal se refere aos progressos solidários entre as operações individuais e sociais. 
[...] se o progresso lógico anda assim ao lado da socialização, deve-se dizer que a criança se torna capaz de operações racionais, posto que seu desenvolvimento social a torna apta à cooperação, ou deve-se admitir, pelo contrário, que são estas aquisições lógicas individuais que lhe permitem as outras e que a conduzem assim a cooperação? Pois as duas espécies de progresso andam exatamente lado a lado, a questão parece sem solução, exceto dizendo que constituem dois aspectos indissociáveis de uma única e só realidade, ao mesmo tempo social e individual. É o que se deve responder, mas com as precisões que vão agora tornar possível a aplicação completa dos meios de análise que nos oferece a noção de "agrupamento" (Piaget, 1977, p. 158).

Portanto, Piaget, após reconhecer a natureza profunda e espontânea da ação construtiva do indivíduo - ações organizadas sob formas de sistemas e composições operatórias - entende que as relações interindividuais não poderiam agir de qualquer modo sobre o indivíduo para conduzir ao conhecimento do mundo, menos ainda de maneira unilateral e arbitrária; pelo contrário, mostra que as ações sociais evoluem também - correlativamente ao desenvolvimento do indivíduo - ao se organizarem sob formas de composições operatórias (cooperações ou operações em comum). Sendo assim, faz sentido falar de uma relação de solidariedade e de irredutibilidade entre as ações intraindividuais e interindividuais, e não de uma simples determinação social ou, inversamente, determinação individual.

Assim, espontaneidade não significa pré-formação endógena (inatismo) nem independência em relação às ações do meio, mas mudanças e construção de estruturas de conhecimento em função das leis de composição interna e das exigências do meio físico e social. É justamente o reconhecimento desse fato que permite a Piaget relativizar e precisar a ação do meio e ir além da solução linear e artificial do senso comum: Piaget privilegia o indivíduo e Vygotsky o meio social.

\section{Conclusões}

1. Se levarmos em conta a produção teórica inicial de Piaget, existe entre ele e Vygotsky um acordo básico sobre a ação do meio social e cultural na explicação do desenvolvimento do pensamento infantil. Contrariamente às afirmações correntes, a evolução do pensamento da criança se explica, para ambos os autores, pela ação de fatores exógenos (pressão do meio social, interação social, etc.) sobre os processos endógenos. A diferença aparece no interesse de Piaget pelos processos de centração - descentração e de Vygotsky pelos processos de interiorização da linguagem.

2. A dimensão mais importante da atividade inicial do indivíduo para Piaget é o conceito de egocentrismo como processo de centração,

Educação \& Realidade, Porto Alegre, v. 38, n. 1, p. 271-292, jan./mar. 2013. 289

Disponível em: <http://www.ufrgs.br/edu_realidade> 
o que não teria sido levado em conta por Vygotsky na sua crítica ao primeiro. Isso explicaria a direção seguida pelas duas teorias na explicação do desenvolvimento psicológico do conhecimento.

3. Para Piaget, a direção da evolução do pensamento não poderia ser do individual para o social - nem o inverso - mas da forma de relação entre os indivíduos, em razão de as transformações operarem como superação dos processos de centração e das estruturas previas. Assim, um sujeito pode estar em contato social com os outros (falando a eles), mas não ter consciência da perspectiva destes, não existindo uma verdadeira troca ou interação social (falando com eles). Por isso, o conceito de socialização para Piaget exige levar em conta uma forma específica de relação, na qual os parceiros, para se comunicarem efetivamente, precisam perceber ou levar em conta o ponto de vista do outro (cooperação).

Segundo Piaget, o conceito de relação social segundo Vygotsky seria amplo demais, pois este não estaria considerando a diferença fundamental entre o caráter centrado ou descentrado das relações entre os indivíduos.

4. Em relação aos conceitos espontâneos e não espontâneos, desfeitos os traços que Vygotsky atribui a Piaget, parece que existem mais aproximações que divergências. Contudo, a partir da sua resposta às críticas feitas por Vygotsky, Piaget destaca processos e mecanismos psicológicos fundamentais que poderiam diferenciar as teorias de ambos. É, justamente, no que diz respeito ao uso dos mecanismos explicativos da formação dos conceitos que as fronteiras entre esses autores se marcam com maior nitidez: a evolução dos conceitos para Vygotsky obedeceria à generalização perceptiva e não à generalização operatória, como postula Piaget, o que permite revelar opções epistemológicas sobre a origem do pensamento e do conhecimento.

Segundo Piaget, não levar em conta o processo de centração e de descentração, bem como utilizar o mecanismo da generalização perceptiva na explicação das transformações do pensamento, conduziria Vygotsky a uma teoria linear do desenvolvimento. Isso tornaria difícil a explicação do avanço dos conhecimentos como processo que relativiza a perspectiva única e reorganiza suas estruturas prévias na constituição de novos sistemas (totalidades) de interpretação.

5. As teses defendidas no início e a renovação da sua obra levaram Piaget a formular uma teoria mais complexa, capaz não de simplesmente negar, mas de superar os reducionismos sociais. Nesse sentido, formula a indissociabilidade e irredutibilidade entre o desenvolvimento das estruturas individuais e coletivas, ou, noutros termos, entre as interações sociais (fatores exógenos) e as interações intraindividuais (fatores endógenos). Em razão disso, não teria sustentação científica o argumento de que para ele existe uma evolução linear do desenvolvimento psicológico que vai da atividade individual para o social. 
6. O presente estudo comparativo conduz à necessidade de se efetuarem estudos mais aprofundados, com vistas a alcançar melhor a singularidade e atualidade do pensamento de ambos os autores. Esses empreendimentos deveriam ter como base a realização de pesquisas comparativas mais pontuais, capazes de esclarecer melhor os alcances das afirmações dos dois autores. Sugerimos, de início, as seguintes pesquisas: processos e mecanismos na formação dos conceitos, papel da ação na gênese do pensamento e da linguagem, relações entre processos intraindividuais e interindividuais na aprendizagem e desenvolvimento dos conceitos espontâneos e científicos, efeitos da instrução na aprendizagem das noções e conceitos científicos.

Recebido em 18 de maio de 2011 Aprovado em 28 de setembro de 2011

\section{Nota}

1 Nos diferentes capítulos desse livro o interlocutor principal ou secundário de Vygotsky é Piaget, sendo que as principais críticas se encontram nos capítulos 2 e 6 . Entre as versões traduzidas ao português e ao espanhol, incluídas nas referências deste trabalho, preferimos a primeira, em razão de não encontrarmos diferenças entre elas.

\section{Referências}

BRONCKARD, Jean-Paul et al. Vygotsky Aujourd'hui. Neuchâtel - Paris: Delachaux \& Niestlé, 1985.

BRONCKARD, Jean-Paul. El Problema de la Consciencia como Analizador de las Epistemologías de Vygotsky y de Piaget. In: SERRAT, Elisabet; ASNAR, Sílvia (Org.). Piaget y Vygotsky Ante el Siglo XXI: referentes de actualidad. Girona: Horsori, 2000. P. 15-41.

MELLO, Suely. A Escola de Vygotsky. In: KESTER, Carrara (Org.). Introdução à Psicología da Educação: seis abordagens. São Paulo: Avercamp, 2008.

PIAGET, Jean. Abstração Reflexionante: relações lógico-matemáticas e ordem das relações espaciais. Porto Alegre: Artes medicas. 1995

PIAGET, Jean. Comentarios Sobre las Observaciones Críticas de Vygotsky. In: VYGOTSKY, Lev Semenovitch. Pensamiento y Lenguaje: teoria del desarrollo cultural de las funciones psíquicas. Buenos Aires: Editorial Lautaro, 1964. P. 167-181.

PIAGET, Jean. La Composition des Forces et le Problème des Vecteurs. Paris: P.U.F. 1973b.

PIAGET, Jean. Le Développement de la Notion de Temp chez L'Enfant. Paris: P.U.F. 1946

PIAGET, Jean. La Direction des Mobiles lors de Chocs et de Poussées. Paris: P.U.F. 1972c.

PIAGET, Jean. Études Sociologiques. Genève: Livraria Droz, 1977.

PIAGET, Jean. A Explicação em Psicologia e o Paralelismo Psicofisiológico. In: FRAISSE, Paul; PIAGET, Jean. Tratado de Psicologia Experimental. Rio de Janei-

Educação \& Realidade, Porto Alegre, v. 38, n. 1, p. 271-292, jan./mar. 2013.

Disponível em: <http://www.ufrgs.br/edu_realidade>

291 
ro: Forense, 1969. Volume 1.

PIAGET, Jean. Les Explications Causales. Paris: P.U.F. $1971 \mathrm{~b}$.

PIAGET, Jean. La Formation de la Notion de Força. Paris: P.U.F. 1973a.

PIAGET, Jean. La Genèse de L'idée de Hasard chez L'enfant. Paris: P.U.F. 1951.

PIAGET, Jean. Gênese das Estruturas Lógicas Elementares. Rio de Janeiro: Zahar, 1971b.

PIAGET, Jean. Introduction à L'Èpistémologie Génétique. Paris: P.U.F. 1974.

PIAGET, Jean. O Juízo Moral na Criança. São Paulo: Summus, 1994.

PIAGET, Jean. O Juízo e Raciocínio na Criança. Rio de Janeiro; São Paulo: Record, 1971a.

PIAGET, Jean. A Linguagem e o Pensamento da Criança. São Paulo: Martins Fontes, 1999.

PIAGET, Jean. O Nascimento da Inteligência na Criança. Rio de Janeiro: Guanabara, 1987.

PIAGET, Jean. Les Notions de Mouvement et de Vitesse chez l'Enfant. Paris: P.U.F. $1972 b$.

PIAGET, Jean. Recherches sur la Contradiction. Paris: P.U.F. 1974a.

PIAGET, Jean. Recherches sur la Généralisation. Paris: P.U.F. 1978.

PIAGET, Jean. La Représentation du Monde chez l'Enfant. Paris: Alcan, 1996.

PIAGET, Jean. A Tomada de Consciência. São Paulo: Melhoramentos/ Ed. USP. 1974b

PIAGET, Jean. La Transmission dês Mouvements. Paris: P.U.F. 1972a.

PIAGET, Jean; BARBEL, Inhelder. O Desenvolvimento das Quantidades Físicas na Criança. Rio de Janeiro: Zahar, 1983.

PIAGET, Jean; INHELDER, Barbel. A Representação do Espaço na Criança. Porto Alegre: Artes Médicas, 1993.

PIAGET, Jean; INHELDER, Barbel; SZMINSKA, Alina. La Géométrie Spontanée de L'enfant. Paris: P.U.F., 1948.

PIAGET, Jean; SZEMINSKA, Alina. Gênese do Número na Criança. Rio de Janeiro: zahar, 1981,

REGO, Teresa. Vygotsky: uma perspectiva histórico-cultural da educação. Petrópolis: Vozes, 2002.

VYGOTSKY, Lev Semenovitch. Pensamento e Linguagem. São Paulo: Martin Fontes, 1991.

VYGOTSKY, Lev Semenovitch. Pensamiento y Lenguaje: teoria del desarrollo cultural de las funciones psíquicas. Buenos Aires: Editorial Lautaro, 1964.

Adrian Oscar Dongo-Montoya é mestre em Psicologia Social pela USP. É doutor em Psicologia Escolar pela USP, com Pós-doutorado na Université LYON-II - França e Livre docente em Psicologia do Desenvolvimento pela UNESP. É professor Titular do Departamento de Psicologia da Educação da Faculdade de Filosofia e Ciências da UNESP - Campus de Marília, na cidade de Marília, estado de São Paulo.

E-mail: dongomontoyaa@pop.com.br 